\title{
Influence of foliar chemical compounds on the development of Spodoptera litura (Fab.) in interspecific derivatives of groundnut
}

\author{
N. Mallikarjuna ${ }^{1}$, K. R. Kranthi ${ }^{2}$, D. R. Jadhav ${ }^{1}$, S. Kranthi ${ }^{2}$ and S. Chandra ${ }^{1}$ \\ ${ }^{1}$ International Crops Research Institute for the Semi-Arid Tropics (ICRISAT), Patancheru, Andhra Pradesh, \\ India; ${ }^{2}$ Central Institute for Cotton Research, Nagpur, Maharashtra, India
}

Ms. received: November 12, 2002; accepted: July 15, 2003

\begin{abstract}
Tobacco armyworm, Spodoptera litura (Fab), a polyphagous insect, is an important pest of groundnut (Arachis hypogaea L). It is one of the insect pests which had developed resistance to insecticides. Currently there are no cultivars of groundnut which express high level of resistance to $S$. litura. Wild species of groundnut, which show high levels of resistance, have been identified. Arachis kempff-mercadoi is one such wild species, which is reported to be resistant to $S$. litura, and indicated that in wild species three flavonoids chlorogenic acid, quercetin and rutin are involved in the components of resistance. In the present study, although these flavonoids had an effect on larval mortality, statistical analysis revealed that quercetin had a major effect due to high correlation of quercetin with chlorogenic acid and rutin. Interspecific derivatives were obtained as a result of crossing cultivated groundnut with A. kempff-mercadoi. In vitro studies showed high percentage of neonate larval mortality when fed on the foliage of interspecific derivatives, majority of interspecific derivatives were detrimental to larval development and had considerable effect on its subsequent progeny. Resistant derivatives were found to have high levels of flavonoids and antibiosis mechanism prevented larval growth. Susceptible derivatives and the female parent, A. hypogaea have low levels of flavonoids.
\end{abstract}

Key words: spodoptera litura, A. kempff-mercadoi, wild species, flavonoids, resistance

\section{Introduction}

Groundnut (Arachis hypogaea L.) is one of the world's principal oilseed crops. It is attacked by many species of insects which cause damage ranging from incidental feeding to near total plant destruction and yield loss (Smith and Barfield, 1982; Stalker and Campbell, 1983; Wightman and Amin, 1988; Wightman et al., 1989; Wightman and Ranga RaO, 1994; Lynch and Mack, 1995). Amongst them, the tobacco armyworm, Spodoptera litura (Fab.) is a polyphagous insect, whose reproductive capacity and migration ability over long distances has made it economically an important pest of many agricultural crops, with a wider geographic range throughout Asia, from north Africa to Japan, Australia and New Zealand (FEAKIN, 1973). It has been reported to attack over 112 cultivated plant species and about 60 species are from India (GARAD et al., 1984). In India, it has become particularly notorious in most tobacco-growing regions. In the last three and half decades, however, it has extended its host range to other crops such as cotton, mungbean, soya bean, cabbage and leafy vegetables, including groundnut (MAREE et al., 1999). Groundnut yield losses up to 71\% have been reported in the irrigated tracts of Andhra Pradesh, Karnataka and Tamil Nadu, the southern states of India (NAIR, 1986; Amin, 1988). Yield losses of groundnuts have been directly associated with higher density of larvae of $S$. litura, and the intensity of defoliation (Panchbhavi and Nethradani RaJ, 1987).

Adults of S. litura lay around 2000 eggs on the abaxial surface of groundnut leaves, in batches of 200-300 each. The larval and pupal periods take 20 and 7-10 days, respectively. The total life cycle is completed in 30 days (GAHUKAR, 1992). There may be as many as 12 generations annually in southern India (Wightman and Amin, 1988). During daytime the larvae usually hide under the clods at the plant base, climb the plants only after dusk, and feed in the night and early hours of dawn (SAINI and Verkya, 1985). They migrate in large numbers in search of new crop(s) or other host plants, when there is a shortage of food. Continuous cropping of summer crops and vegetables provides food for the larvae, and the pupae do not aestivate in extreme temperatures (Ranga Rao et al., 1989).

Spodoptera litura is one of the first insect pests of agricultural importance in India to develop resistance to insecticides. In the early 1980 s, the pest populations in Andhra Pradesh and further south in Tamil Nadu were highly resistant to lindane, endosulfan, carbaryl and malathion, and synthetic pyrethroids then available to commercial farmers (RAMAKRISHNAN et al., 1984), and mid-1990s (Armes et al., 1997) and more recently (Kranthi et al., 2002). Since that time it has become 
increasingly an important pest of groundnut, particularly in the east coast of peninsular India.

Currently, no cultivars of groundnut are known to express resistance to $S$. litura. However, some wild relatives of groundnut were found resistant to $S$. litura. Neonate larvae suffer high levels of mortality and the development of older larvae on resistant wild species is severely inhibited (Stevenson et al., 1993b). Larvae exposed to excised leaves of wild species lose weight, which is not significantly different from that of those deprived of food for $24 \mathrm{~h}$. These results suggest that the leaves are unpalatable and/or detrimental to their growth (Stevenson et al., 1993a). This has resulted in providing ample research opportunities at ICRISAT to exploit the genetic diversity of wild Arachis species. The focus has been shifted to evaluate the wider genetic pool with desirable agronomic traits and identify potential sources of resistance to $S$. litura.

The identification factors in the foliage of wild species of Arachis that affect the feeding behaviour and development of $S$. litura may provide plant breeders and biotechnologists with valuable information for the development of cultivars of Arachis with high degree of resistance to $S$. litura.

Chlorogenic acid and rutin inhibit the development of neonate lepidopterous larvae and their potential role in the natural resistance in crops (ElLIGER et al., 1980, 1981; Wiseman et al., 1990; Yang et al. 1993). STEvenson et al. (1993a) identified that both the physical and chemical factors present in the wild species of groundnut, Arachis kempff mercadoi are involved in resistance to $S$. litura. They also reported that the methanol extract of the foliage of wild Arachis species such as Arachis paraguariensis, Arachis appresipila and Arachis chacoensis significantly inhibited the larval development indicating that phytochemicals were responsible. Leaves of the resistant wild species have greater biting effect than leaves of susceptible cultivars. In view of the similarity of rutin and chlorogenic acid contents isolated from the foliage of wild species of groundnut, they were used in insect bioassays (STEVEnson, 1992a).

In the present investigation, quercetin, chlorogenic acid, and rutin were assayed both in the parents [A. kempff-mercadoi (resistant) and A. hypogaea (susceptible)] as well as in the interspecific derivatives from the cross, Arachis hypogaea $\times$ A. kempff-mercadoi. The wild resistant progeny as well as $A$. kempff-mercadoi showed the presence of all the flavonoids in greater proportion than in the susceptible $A$. hypogaea used in this study. This study also confirms that the resistance present in wild species effectively can be transferred to the progeny even after crossing with susceptible A. hypogaea.

\section{Materials and Methods}

\subsection{Insect rearing}

Spodoptera litura egg masses were collected from the groundnut crop grown in the experimental blocks at the ICRISAT farm. On eclosion, the neonate larvae were reared on a semi-synthetic diet based on chickpea flour and dried sorghum leaves at $25 \pm 2{ }^{\circ} \mathrm{C}$ and $14 \mathrm{~L}: 10 \mathrm{D}$. Three to four pairs of adults were released for oviposition in a cylindrical cage, and provided with $10 \%$ sucrose solution. The neonate larvae hatched from the egg masses were used in the experiments.

\subsection{Interspecific derivatives}

During the rainy season of $2000-01,23$ interspecific derivatives from the cross $A$. hypogaea $\times A$. kempff-mercadoi including resistant check wild species, A. kempff-mercadoi and the susceptible parent, $A$. hypogaea, were propagated by seeds in the screenhouse at $28 \pm 2{ }^{\circ} \mathrm{C}, 55 \pm 5 \% \mathrm{RH}$ (table 1). The first, third and seventh leaflets from the base from interspecific derivatives were excised, and arranged in a circle in a round pot (4" diameter), which was kept moist.

\subsection{Insect bioassays on leaflets}

Twelve neonate larvae of $S$. litura were released inside a round pot (4" diameter), and covered with a transparent polythene cover to test their survival on each leaflet. The experimental pots were then transferred to an incubator maintained at $25 \pm 2{ }^{\circ} \mathrm{C}, 14 \mathrm{~L}: 10 \mathrm{D}$ and $70 \% \mathrm{RH}$. The experiment was replicated with three leaflets per pot. Leaflets were observed for mortality and duration of larvae, recorded for weights and duration of pupae, and adult emergence. Previous studies have shown that data from larval growth and behaviour on excised leaves provides information which precisely reflects the effect of the unexcised leaves in the field (Stevenson, 1992b).

\subsection{Extraction of chlorogenic acid, quercetin and rutin from groundnut leaflets}

Basal first, third and seventh leaflets from interspecific derivatives and their parents were oven-dried for 60 minutes, before powdered. Hundred milligrams of the powder was extracted in $1 \mathrm{ml}$ of $90 \%$ methanol overnight. The extractions

Table 1. Interspecific crosses of Arachis species investigated for resistance to Spodoptera litura

\begin{tabular}{|c|c|c|}
\hline $\begin{array}{l}\text { Interspecific } \\
\text { cross }\end{array}$ & Identity & Generation \\
\hline D 1 & ICGS $44 \times$ ICG 8959 self & F3 \\
\hline D 2 & ICGS $44 \times$ ICG 8959 self & F3 \\
\hline D 5 & ICGS $44 \times$ ICG 8959 self & F3 \\
\hline D 7 & ICGS $44 \times$ ICG 8959 self & F3 \\
\hline D 11 & ICGS $44 \times$ ICG 8959 self & F3 \\
\hline D 16 & $(\mathrm{ICGS} 44 \times$ ICG 8959) $\times$ ICGS 44 & $\mathrm{F} 2 \mathrm{BC} 1$ \\
\hline D 19 & $(\mathrm{ICGS} 44 \times$ ICG 8959$) \times$ ICGS 44 & $\mathrm{~F} 2 \mathrm{BC} 1$ \\
\hline D 20 & $($ ICGS $44 \times$ ICG 8959) $\times$ ICGS 44 & $\mathrm{F} 2 \mathrm{BC} 1$ \\
\hline D 21 & $($ ICGS $44 \times$ ICG 8959) $\times$ ICGS 44 & $\mathrm{F} 2 \mathrm{BC} 1$ \\
\hline D 22 & $($ ICGS $44 \times$ ICG 8959) $\times$ ICGS 44 & $\mathrm{F} 2 \mathrm{BC} 1$ \\
\hline D 25 & $($ ICGS $44 \times$ ICG 8959$) \times$ ICGS 44 & $\mathrm{~F} 2 \mathrm{BC} 1$ \\
\hline D 26 & $($ ICGS $44 \times$ ICG 8959) $\times$ ICGS 44 & $\mathrm{F} 2 \mathrm{BC} 1$ \\
\hline D 34 & $(\mathrm{ICGS} 44 \times$ ICG 8959) $\times$ ICGS 44 & $\mathrm{F} 2 \mathrm{BC} 1$ \\
\hline D 57 & $($ ICGS $44 \times$ ICG 8959) $\times$ ICGS 44 & $\mathrm{F} 2 \mathrm{BC} 1$ \\
\hline D 69 & $($ ICGS $44 \times$ ICG 8959) $\times$ ICGS 44 & $\mathrm{F} 2 \mathrm{BC} 1$ \\
\hline D 77 & $(\mathrm{ICGS} 44 \times$ ICG 8959$) \times \mathrm{ICGS} 44$ & $\mathrm{~F} 2 \mathrm{BC} 1$ \\
\hline D 78 & $($ ICGS $44 \times$ ICG 8959) $\times$ ICGS 44 & $\mathrm{F} 2 \mathrm{BC} 1$ \\
\hline D 85 & $(\mathrm{ICGS} 44 \times$ ICG 8959$) \times$ ICGS 44 & $\mathrm{~F} 2 \mathrm{BC} 1$ \\
\hline D 94 & $($ ICGS $44 \times$ ICG 8959) $\times$ ICGS 44 & $\mathrm{F} 2 \mathrm{BC} 1$ \\
\hline D 96 & $(\mathrm{ICGS} 44 \times$ ICG 8959$) \times$ ICGS 44 & $\mathrm{~F} 2 \mathrm{BC} 1$ \\
\hline D 104 & $($ ICGS $44 \times$ ICG 8959) $\times$ ICGS 44 & $\mathrm{F} 2 \mathrm{BC} 1$ \\
\hline ICGS 44 & A. hypogaea cultivar & Female parent \\
\hline 30085 & A. Kempff-mercadoi; wild species & Male parent \\
\hline
\end{tabular}


were repeated with hexane to get rid of waxes and chlorophyll. After centrifugation, the methanolic extract (supernatant) was concentrated to dryness on a water bath. The residue was redissolved in $100 \mu \mathrm{l}$ methanol and $3 \mu \mathrm{l}$ of the mixture was spotted on a silica gel thin layer chromatography (TLC) plates and run in butanol : acetic acid : water (BAW) $(4: 1: 5)$. Rutin, quercetin and chlorogenic acid were run as standards on TLC. The corresponding spots were scraped and re-extracted in $800 \mu \mathrm{l}$ of methanol. After centrifugation, $600 \mu \mathrm{l}$ of methanolic extract of each of the spots was read at $366.5 \mathrm{~nm}$ for quercetin, 352.5 for rutin, and 324 for chlorogenic acid. Later, the chlorogenic acid fractions were used for colorometric tests at $515 \mathrm{~nm}$ using Arnow's reagent. Similarly, the quercetin and rutin fractions were tested colorimetrically using Fast blue B salt. All the samples were estimated thrice.

\subsection{Biometric analysis}

Data on each biological character were subjected to one-way analysis of variance to assess the statistical significance of differences among the 23 genotypes ( 21 interspecific derivatives and their two parents). The means were separated following Duncan's multiple range test (DMRT) (Duncan, 1951). Relationship of mortality with chlorogenic acid (C), quercetin $(\mathrm{Q})$, and rutin $(\mathrm{R})$ was investigated using appropriate regression analysis methods based on data from the 23 interspecific derivatives. Mortality of larvae was highly correlated with $\mathrm{C}(r=0.82, \mathrm{P}<0.001), \mathrm{Q}(r=0.91, \mathrm{P}<0.001)$ and $\mathrm{R}(r=0.83, \mathrm{P}<0.001)$. In addition, there was a significantly high correlation between chlorogenic acid and quercetin $(r=0.88, \mathrm{P}<0.001)$, chlorogenic acid and rutin $(r=0.92, \mathrm{P}<0.001)$ and quercetin and rutin $(r=0.88$, $\mathrm{P}<0.001$ ). This correlation (multi-colinearity) among the independent variables chlorogenic acid, quercetin and rutin tends to inflate the standard errors of the resulting partial regression coefficients, rendering the resulting multiple linear regression equation of mortality on chlorogenic acid, quercetin and rutin unreliable. Path analysis (Kempthorne, 1957) and step-wise regression (DRAPER and SмITH, 1966) were therefore used to assess the relationship of mortality with quercetin, chlorogenic acid and rutin. The latter enabled to identify the important ones among chlorogenic acid, quercetin and rutin. The former, a standardized multiple regression analysis technique, enabled to quantify the direct and indirect effects of each of chlorogenic acid, quercetin and rutin on mortality.

\section{Results}

Significant differences were observed between interspecific derivatives of groundnut on the mortality of neonate larvae of $S$. litura. Among the 23 interspecific derivatives (D), survival of neonate larvae was significantly low on D 20, D 85, and D 94 (fig. 1). In contrast no mortality was noticed on D 5, D 25 and D 77, which were significantly not different from the susceptible check, A. hypogaea cv. ICGS-44. However, more than $60 \%$ of the neonate larvae failed to survive on D 16, D 57, D 78 and the resistant parent, A. kempff-mercadoi 30085 (table 2).

The step-wise regression, both forward and backward, consistently identified quercetin as the major variable to affect larval mortality, alone accounting for $82 \%$ of variation in larval mortality (adjusted $\left.R^{2}=0.82\right)$. This is expected due to high correlation of quercetin with chlorogenic acid and rutin, rendering chlorogenic acid and rutin untenable to describe the variation in larval mortality. In fact, addition of either or both rutin and chlorogenic acid in the multiple regression equation produced an adjusted $R^{2}$ which was in fact lower when quercetin alone was in the equation.

Based on path analysis, quercetin has shown a direct effect of 0.78 , and indirect effect through chlorogenic acid and rutin being -0.04 and 0.17 , respectively. Interestingly, despite a strong correlation between larval mortality and chlorogenic acid, the direct effect of chlorogenic acid on larval mortality was only -0.04 , with its indirect effect on larval mortality through quercetin and rutin being 0.68 and 0.18 , respectively. Similarly, in spite of a strong correlation between larval mortality and rutin, the direct effect of rutin on larval mortality was only 0.19 , with its indirect effect on larval mortality through quercetin and chlorogenic acid being 0.68 and -0.04 , respectively. This was also strongly supported by the step-wise regression in clearly establishing that quercetin is the major factor accounting for variation in larval mortality.

The development of neonate larvae that fed on D 16, D 20, D 22, D 57, D 78, D 85, and D 94 contained high quantities of chlorogenic acid, rutin and quercetin was severely impeded compared with the susceptible parent, $A$. hypogaea (table 3 ). Furthermore, the inhibitory effect in D 57 and D 78 in quercetin (fig. 2), D 57, D 78 and D 22 in chlorogenic acid (fig. 3), and D 57 and D 78 in rutin (fig. 4) contents, but D 57 all produced malformed adults. However, quercetin and rutin showed their individual effect on the mortality and
Fig. 1. Spodoptera litura neonate larval mortality on interspecific derivatives from the crosses A. hypogaea ICGS44 × A. kemph mercadoi

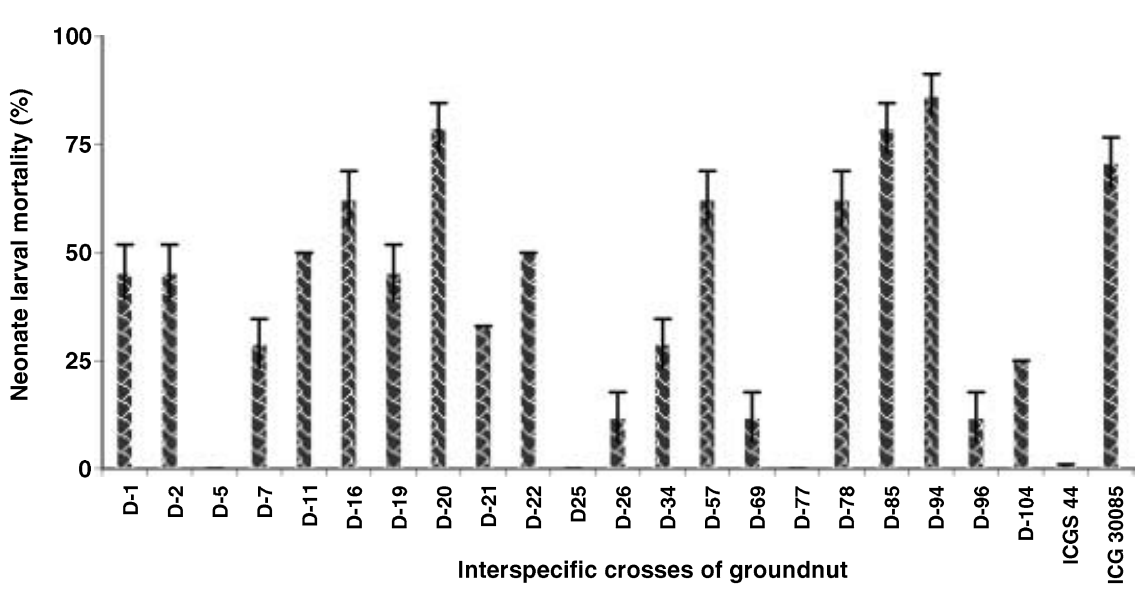




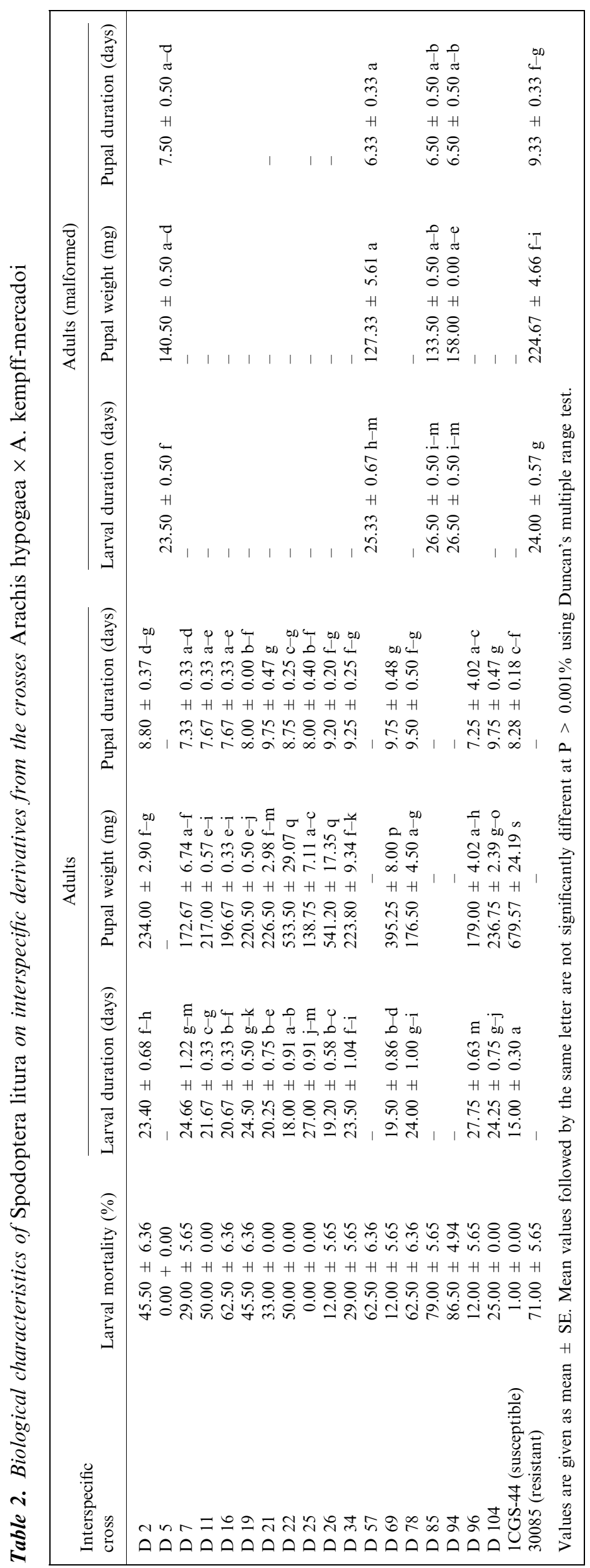


Table 3. Thin layer chromatographic analysis of quercetin, chlorogenic acid and rutin compounds extracted from interspecific derivatives, susceptible and resistant parents of Arachis

\begin{tabular}{|lccc|}
\hline Interspecific & $\begin{array}{c}\text { Quercetin } \\
\text { cross/parent }\end{array}$ & $\begin{array}{c}\text { Chlorogenic } \\
\text { acid }(\mu \mathrm{g} / \mathrm{ml})\end{array}$ & $\begin{array}{c}\text { Rutin } \\
(\mu \mathrm{g} / \mathrm{ml})\end{array}$ \\
\hline D 1 & 0.66 & 0.30 & 0.30 \\
D 2 & 0.48 & 0.40 & 0.22 \\
D 5 & 0.52 & 0.34 & 0.23 \\
D 7 & 0.47 & 0.26 & 0.24 \\
D 11 & 0.68 & 0.74 & 0.60 \\
D 16 & 0.81 & 0.71 & 0.72 \\
D 19 & 0.56 & 0.60 & 0.51 \\
D 20 & 1.00 & 0.78 & 0.80 \\
D 21 & 0.56 & 0.57 & 0.45 \\
D 22 & 0.71 & 0.72 & 0.71 \\
D 25 & 0.42 & 0.45 & 0.41 \\
D 26 & 0.47 & 0.48 & 0.43 \\
D 34 & 0.43 & 0.34 & 0.33 \\
D 57 & 0.89 & 0.72 & 0.72 \\
D 69 & 0.36 & 0.37 & 0.32 \\
D 77 & 0.31 & 0.33 & 0.24 \\
D 78 & 0.90 & 0.77 & 0.80 \\
D 85 & 0.85 & 0.81 & 0.82 \\
D 94 & 1.10 & 1.12 & 0.84 \\
D 96 & 0.50 & 0.38 & 0.12 \\
D 104 & 0.50 & 0.50 & 0.32 \\
ICGS 44 (susceptible) & 0.40 & 0.47 & 0.21 \\
30085 (resistant) & 1.68 & 1.45 & 1.06 \\
\hline
\end{tabular}

development of larvae. Forty-five percent larval mortality was observed on D 1 , which had $0.7 \mu \mathrm{g} / \mathrm{ml}$ of quercetin, but the levels of rutin and chlorogenic acid were low (table 3). Similar was the case with D 19, which showed $45 \%$ larval mortality at $0.6 \mu \mathrm{g} / \mathrm{ml}$ of quercetin and chlorogenic acid, and at $0.5 \mu \mathrm{g} / \mathrm{ml}$ of rutin.

Among the interspecific derivatives, the larval duration was longer on D 25 and D 96, but not different from D 7, D 19, D 78, D104 and the susceptible check, cv. ICGS-44 the duration was only of 15 days. In contrast, A. kempff-mercadoi not only showed greater mortality of larvae but also extended the larval duration to 24 days. Pupal weights were significantly high on the susceptible check, cv. ICGS-44 (679.57 mg) compared with D 7, D 25, D 78, and D 96 with normal adult emergence and D 5, D 57, D 85, and D 94 with lower pupal weights and malformed adults. Interspecific derivatives D 7, D 11, D 16 and D 96 recorded shorter pupal periods with normal adult emergence, followed by D 5, D 57, D 85 and D 94, which gave rise to malformed adults (table 2).

\section{Discussion}

Studies on the mortality of neonate larvae fed on the foliage of interspecific derivatives from the cross A. hypogaea $\times$ A. kempff-mercadoi confirmed the earlier observations of WightMAn and RANGA RAO (1994), who reported neonate mortality on the leaf surface of ICGV 86031. In the present study, $29 \%$ of the larvae survived on $A$. kempff-mercadoi, while some of them had extended the larval duration, and others did neither pupate normally nor normal adults were observed (table 2). These results show that the phytochemicals (substances) in the foliage of $A$. kemphmercadoi (30085-R) may have been inherited to the interspecific derivatives causing mortality at each developmental stage (fig. 5).

Developmental impediment caused by the presence of high quantities of chlorogenic acid, quercetin and rutin $(0.7-0.8 \mu \mathrm{g} / \mathrm{ml})$ in the leaf tissue expressed an effect of $>60 \%$ larval mortality. However, the interspecific crosses D 5 and D 25 showed no mortality of larvae, and possess $0.52 \mu \mathrm{g} / \mathrm{ml}$ of quercetin, and $<0.45 \mu \mathrm{g} / \mathrm{ml}$ of rutin and chlorogenic acid contents (table 3). In A. kempff-mercadoi (30085-R) the quantity of these chemicals ranged $1.06-1.68 \mu \mathrm{g} / \mathrm{ml}$, whereas the quantity was $<0.50 \mu \mathrm{g} / \mathrm{ml}$ in the susceptible female parent (cv. ICGS-44). These results were confirmed by path analysis indicating that quercetin had a direct effect and chlorogenic acid and rutin showed an indirect effect causing larval mortality. In addition, these results also suggest that antibiosis
Fig. 2. Multiple regression analysis of quercetin against neonate mortality of Spodoptera litura in interspecific derivatives of groundnut (numbers correspond to the crosses listed in table 3 )

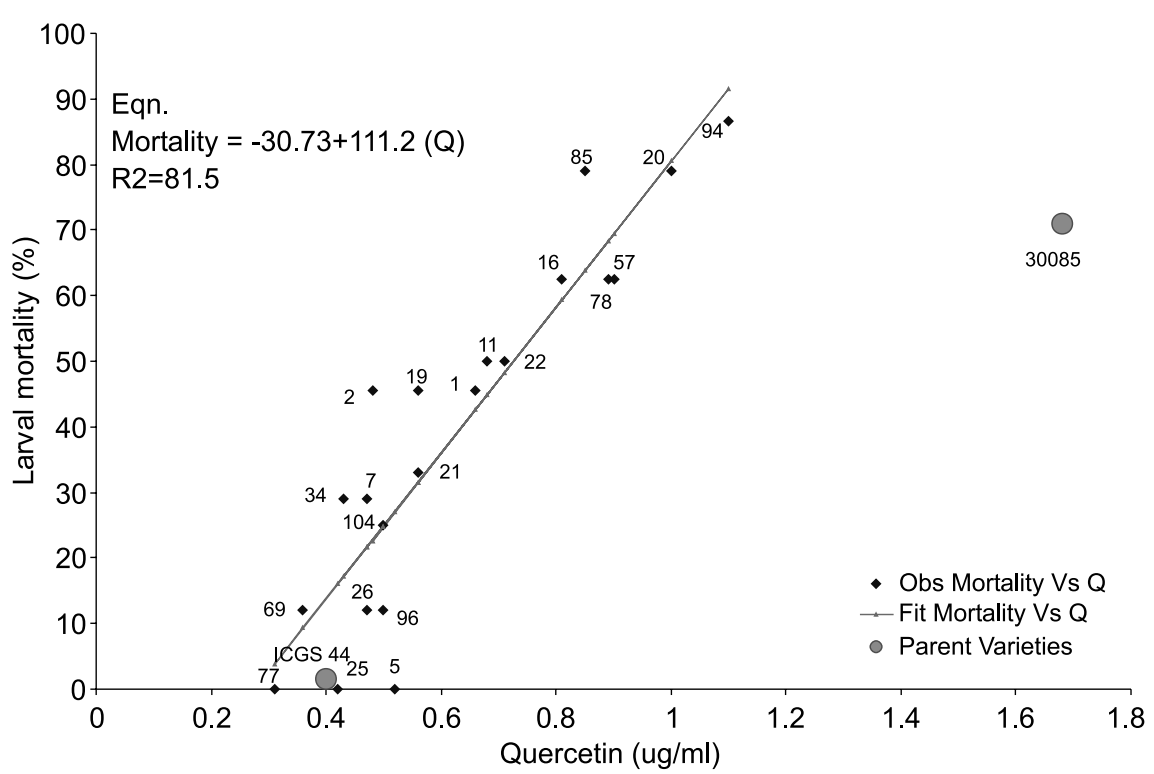



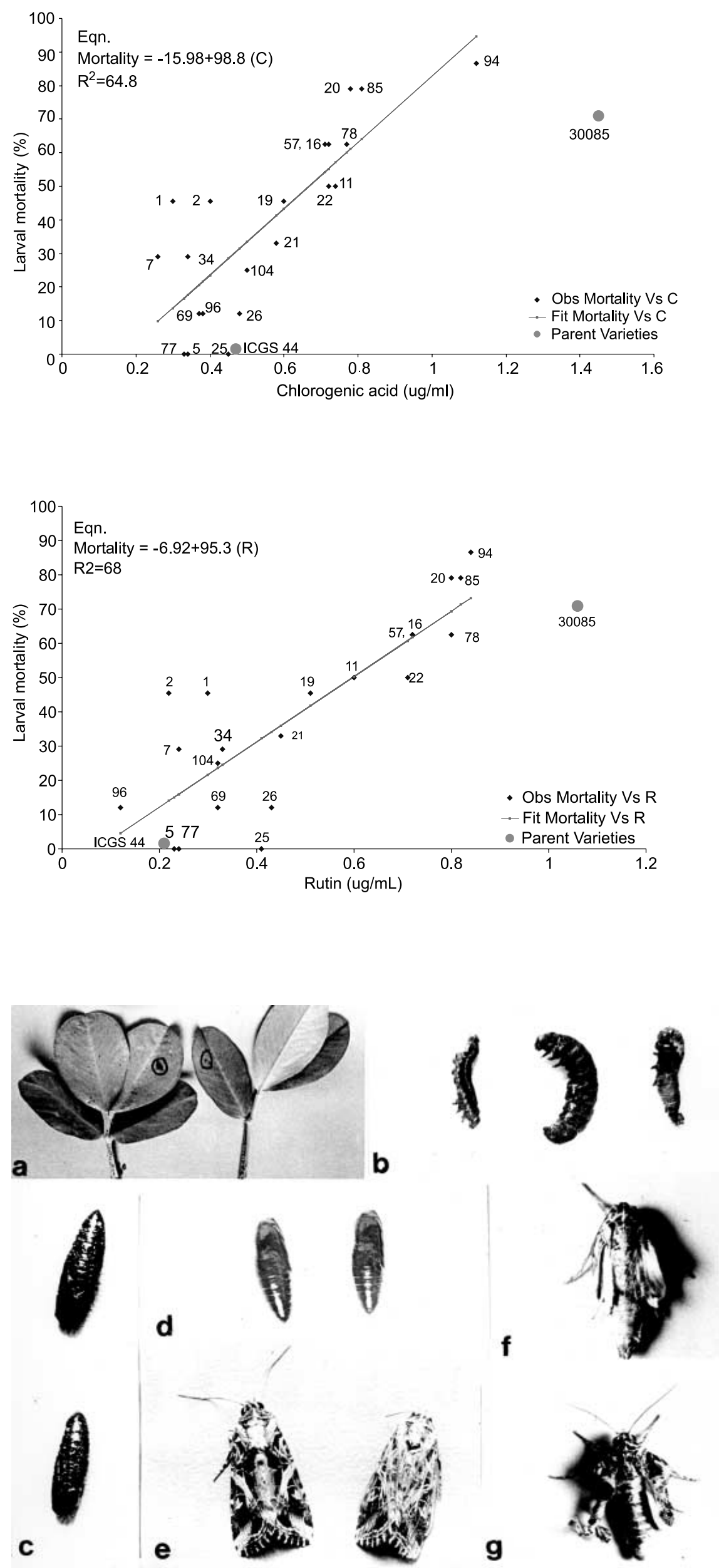

Fig. 3. Multiple regression analysis of chlorogenic acid against neonate mortality of Spodoptera litura in interspecific crosses of groundnut (numbers correspond to the crosses listed in table 3 )

Fig. 4. Multiple regression analysis of rutin against neonate mortality of Spodoptera litura in interspecific crosses of groundnut (numbers correspond to the crosses listed in table 3 )

Fig. 5. Spodoptera litura growth and development on interspecific derivatives from the Arachis hypogaea $x$ A. kempff-mercadoi. (a) Neonate larval death on leaves of interspecific derivative. (b) Abnormality in larval-pupal transformation.

(c) Normal pupae.

(d) Abnormal pupae.

(e) Normal adult.

(f) Malformed adult.

(g) Malformed adult 
factors are involved in extending the duration of both larvae and pupae, besides causing mortality of larvae, and reduction in pupal weights. These factors influenced not only abnormal development of larvae but also expressed their continued effect in terms of malformed pupae and adults (fig. 5).

Greater mortality of neonate larvae and retarded development of older larvae was observed on excised leaves of wild Arachis species on S. litura (STEVENSON et al., 1993a), and fall armyworm, Spodoptera frugiperda (LYNCH et al., 1981; GARNER and LYNCH, 1981). The absence of effects of chlorogenic acid contents on the development of Spodoptera eridania in larval mortality recorded by LindRoth and PETERSEN (1988) may be due to testing of older instars.

Antibiosis effect was predominantly noticed against the larvae of $S$. litura among the several interspecific derivatives of groundnut. However, the magnitude in response to survival and duration of larvae, consumption of foliage, and pupal weights varied among the derivatives of interspecific crosses. In the present study, majority of the interspecific derivatives expressed resistance to $S$. litura with leaf surface exudates immobilizing the larvae, while the chemical effects cannot be excluded. Collectively, the data suggest that extended duration and decreased survival of larvae, reduction in pupal size and weights, induction of deformation, reduced fecundity of adults, and nonhatching of the eggs in majority of the leaflets in interspecific crosses are contained within leaflets. Although emergence of normal adults was observed (table 2), they may either have failed to produce progeny due to male sterility or the progeny larvae had prolonged duration to become pupae, which appears to be the transition phase and host sensitivity to nutritional quality. Similar results were obtained with $S$. frugiperda when fed on peanut foliage (LEUCK and SKInNER, 1971) and Spodoptera littoralis when fed on wild tomato, Lycopersicon pennellii expressing adult deformity (BERLINGER et al., 1997).

The present investigation has clearly demonstrated the involvement of quercetin, chlorogenic acid and rutin, and their significant impact on the development and mortality of neonate larvae of $S$. litura on interspecific derivatives of Arachis species. They may also help not only in combating other lepidopteran pests on groundnut, but also in formulating new pest management strategies with greater emphasis on hostplant resistance.

\section{Acknowledgements}

Discussion with Dr G. V. Ranga RaO, Senior Entomologist, ICRISAT, on planning of insect bioassays, and the technical assistance provided by $\mathrm{Mr} \mathrm{V}$. Balakrishna and $\mathrm{Mr}$ N. Laxmaiah are gratefully acknowledged.

\section{References}

Amin, P. W., 1988: Insect and mite pests and their control. In: Groundnut. Ed. by Reddy, P. S. New Delhi, India: Indian Council of Agricultural Research, 393-452.
Armes, N. J.; Wightman, J. A.; Jadhav, D. R.; Ranga Rao, G. V., 1997: Status of insecticide resistance in Spodoptera litura in Andhra Pradesh, India. Pest. Sci. 50, 240-248.

Berlinger, M. J.; TAmim, M.; Tal, M.; Miller, R., 1997: Resistance mechanisms of Lycopersicon pennellii accessions to Spodoptera littorallis (Boisduval) (Lepidoptera: Noctuidae). J. Econ. Entomol. 90, 1690-1696.

Draper, N. R.; SMith, H., 1966: Applied Regression Analysis. New York: John Wiley \& Sons.

Duncan, D. B. 1951: A significant test for differences between ranked treatments in an analysis of variance. Virginia $\mathbf{J}$. Sci. 2, 171-189.

Elliger, C. A.; Wong, Y.; Waiss, A. C. 1980: Flavonoids as larval growth inhibitors: structural features governing toxicity. Naturwissenschaften 67, 358-360.

Elliger, C. A.; Wong, Y.; Chan, B. G.; Waiss, A. C. 1981: Growth inhibitors in tomato (Lycopersicon) to tomato fruitworm (Heliothis zea). J. Chem. Ecol. 7, 753-760.

FEAKIn, S. D., 1973: Pest Control in Groundnuts. PANS Manual, 3rd edn. London: Centre for Overseas Pest Research, Overseas Development Administration.

GahuKar, R. T., 1992: Groundnut entomology: retrospect and prospect. Agric. Zool. Rev. 5, 139-199.

Garad, G. P.; Shivpuje, P. R.; Bilapte, G. G., 1984: Life fecundity tables of Spodoptera litura (F.) on different hosts. Proc. Indian Acad. Sci. 93, 29-33.

Garner, J. W.; Lynch, R. E., 1981: Fall armyworm leaf consumption and development on Florunner peanuts. J. Econ. Entomol. 74, 191-193.

Kempthorne, O., 1957: An Introduction to Genetic Statistics. John Wiley \& Sons., Inc., New York. 286-289.

Kranthi, K. R.; Jadhav, D. R.; Kranthi, S.; Wanjari, R. R.; Ali, R. R.; Russell, D. A., 2002. Insecticide resistance in five major insect pests of cotton in India. Crop Prot. 21, $449-460$.

Leuck, D. B.; Skinner, J. L., 1971: Resistance in peanut foliage influencing fall armyworm control. J. Econ. Entomol. 64, 148-150.

Lindroth, R. L.; Petersen, S. S., 1988: Effects of plant phenols on performance of southern armyworm larvae. Oecologia 75, 185-189.

LyNCH, R. E.; MACK, T. P., 1995: Biological and biotechnological advances for insect management in peanut. In: Advances in Peanut Science. Ed. by Pattee, H. E.; Stalker, H. T. Stillwater, Oklahoma, USA: American Peanut Research and Education Society Inc., 95-159.

Lynch, R. E.; Branch, W. D.; Garner, J. W., 1981: Resistance of Arachis species to the fall armyworm, Spodoptera frugiperda. Peanut Sci. 8, 106-109.

Maree, J. M.; Kallar, S. A.; Khuhro, R. D., 1999: Relative abundance of Spodoptera litura F. and Agrotis ypsilon Rott. on cabbage. Pakistan. J. Zool. 31, 31-34.

NAIR, M. R. G. K., 1986: Insects and Mites of Crops in India. New Delhi, India: Indian Council of Agricultural Research.

Panchbhavi, K. S.; Nethradani Raj, C. R., 1987: Yield of groundnut as affected by varying larval density of Spodoptera litura (Fabricius) (Lepidoptera: Noctuidae). Indian J. Agric. Sci. 57, 525-527.

Ramakrishnan, N.; Saxena, V. S.; Dhingra, S., 1984: Insecticide resistance in the population of Spodoptera litura $(\mathrm{F}$. in Andhra Pradesh. Pesticides 18, 23-24.

Ranga Rao, G. V.; Wightman, J. A.; Ranga Rao, D. V., 1989: Threshold temperatures and thermal requirements for the development of Spodoptera litura (Lepidoptera: Noctuidae). Environ. Entomol. 18, 548-551. 
SAINI, S. S.; Verkya, O. P., 1985: Some observations on occurrence of tobacco caterpillar, Spodoptera litura (Fabricius) on groundnut during kharif, 1983 in Punjab. Pl. Prot. Bull. 37, 31.

Smith, J. W., Jr; Barfield, C. S., 1982: Management of preharvest insects. In: Peanut Science and Technology. Ed. by Pattee, H. E.; Young, C. T. Yoakum, Texas, USA: American Peanut Research and Education Society, Inc., 250-325.

Stalker, H. T.; Campbell, W. V., 1983: Resistance of wild species of peanut to an insect complex. Peanut Sci. 10, 30-33.

Stevenson, P. C., 1992a: Resistance mechanisms in wild and cultivated species of Arachis L. to Spodoptera litura Fab. (Lepidoptera: Noctuidae). PhD thesis, London, UK: University of London.

Stevenson, P. C., 1992b: Biochemical resistance in wild species of groundnut (Arachis) to Spodoptera litura (Lepidoptera: Noctuidae). In: Proceedings of the VI Meeting of the IOBC/EUCARPIA Working Group on 'Breeding for Resistance to Insects and Mites'. Sept. 1992, Warwick, UK: Warwick University, 155-162.

Stevenson, P. C.; Anderson, J. C.; Blaney W. M.; Simmonds M. S. J., 1993a: Developmental inhibition of Spodoptera litura (Fab.) larvae by a novel caffeoylquinic acid from the wild groundnut Arachis paraguariensis (Chod et Hassl.). J. Chem. Ecol. 19, 2917-2933.

Stevenson, P. C.; Blaney, W. L.; Simmonds, M. S. J.; Wightman, J. A., 1993b: The identification and charac- terization of resistance in wild species of Arachis to Spodoptera litura (Lepidoptera: Noctuidae). Bull. Ent. Res. 83, 421-429.

Wightman, J. A., Amin, P. W., 1988: Groundnut pests and their control in the semi-arid tropics. Trop. Pest. Manag. 34, 218-226.

Wightman, J. A.; Ranga Rao, G. V., 1994: Groundnut pests. In: The Groundnut Crop: A Scientific Basis for Improvement. Ed. by SMARTt, J. London: Chapman \& Hall, 395479 .

Wightman, J. A.; Amin, P. W.; Rao, G. V. R.; Dick, K. M., 1989: Pests of groundnut in the semi-arid tropics. In: Insect Pests of Tropical Food Legumes. Ed. by SINGH, S. R. New York, USA: John Wiley, 243-322.

Wiseman, B. R.; Isenhour, D. J., 1990: Effects of resistant corn silks on corn earworm (Lepidoptera: Noctuidae) biology: a laboratory study. J. Econ. Entomol. 83, 614-617.

Yang, G.; Espelie, K. E.; Todd, J. W.; Culbreath, A. K.; Pittman, R. N.; Demski, J. W., 1993: Cuticular lipids from wild and cultivated peanuts and the relative resistance of these peanut species to fall armyworm and thrips. J. Agric. Food Chem. 41, 814-818.

Author's address: Dr. N. Mallikarjuna, Senior Scientist, ICRISAT, Patancheru, 502 324, A. P., India. E-mail: N.mallikarjuna@CGIAR.ORG. Telephone: +91-40-2329 6162, Ext: 2328; Fax No.: +91-8455-282828. 
Copyright of Journal of Applied Entomology is the property of Blackwell Publishing Limited and its content may not be copied or emailed to multiple sites or posted to a listserv without the copyright holder's express written permission. However, users may print, download, or email articles for individual use. 